\title{
A Novel Way of Integrated Risk Awareness based on the Internet of Things for Intelligent Crime Prevention
}

\author{
Donghyeok Suh ${ }^{1}$, Kyung-soo $\mathrm{Cho}^{2}$ and Jeong-hwa Song ${ }^{2}$ \\ 1119, Dandae-ro, Dongnam-gu, Cheonan-si, Chungnam,31116, Korea \\ 291, Daehak-ro, Seonghwan-eub, Seobuk-gu, Cheonan-si, \\ Chungnam,31020, Korea \\ ${ }^{1}$ dhsuh122@dankook.ac.kr, ${ }^{2}\{k s c h o$, songjh\}@nsu.ac.kr
}

\begin{abstract}
IoT has been applied to various fields such as medicine, tourism, logistics and education. In this study, we suggested that both the environmental factors and the human factors should be considered in order to prevent crime by using IoT. Environmental improvement alone has a limit that the risk of crime is not properly predicted, thereby limiting a chance to avoid the risk. In addition, surveilling human factors alone also has a limitation that it cannot predict the risk of crime. We proposed and analyzed that environmental factors and human factors are closely related and affect the crime itself. In order to demonstrate the validity of this proposal, we analyzed the existing incidents and verify its validity.
\end{abstract}

Keywords: Internet of Things, contextual inferences, crime prevention, contextual recognition, intelligent service

\section{Introduction}

The Internet of Things (IoT) have remarkably achieved network stabilization compared to the previous era of 'Ubiquitous'. In Ubiquitous networking, Zigbee was used as a communication protocol, and there was a difficulty in long distance data transmission and reliable data transmission in obstacles. IoT solves a long-distance transmission problem by utilizing mobile communication networks as well as short distance data communication networks. This makes it possible to transmit event data acquired by a sensor in an IoT environment for a stable short and long-distance transmission.

Based on a stable data communication network, IoT utilizes a wide variety of sensors to detect physical, chemical and biological changes in the real world and to transmit those acquired data, thereby contributing to contextual inferences of the vast objects and environment of the real world. IoT has been applied to various fields of industry such as automotive, medical, tourism, and has caused a great change in the field. Along with Big Data and Artificial Intelligence, IoT is destroying the basic concepts of each industry, and creating new services and new business models. As a result, users have had a beneficial experience that they have never experienced before. As in other areas, IoT can be utilized as a measure to further strengthen crime prevention. The United States and the United Kingdom have already applied various information and communication technologies to quickly detect risks and to ensure the safety of their citizens. On the other hand, various methods are being studied for crime prevention. Urban environment design research for crime prevention is proceeding as part of such efforts.

This study was based on the assumption that crime can be prevented by adjusting urban spatial factors. This study then analyzed the spatial characteristics of cities in various ways, changes the structure of spaces with a large number of factors involved in crime

Received (November 15, 2017), Review Result (January 15, 2018), Accepted (January 30, 2018) 
occurrence. This study also suggested to monitor and control access to areas vulnerable to crime to prevent crime.

Meanwhile, intelligent CCTVs have been actively installed nowadays. They are equipped with a function to detect and track delinquent activities of potential criminals in the urban spaces. Compared to previous CCTV that simply records a specific area continuously, the recent intelligent CCTV not only records moving objects but also tracks targets in video.

Crime prevention through urban environmental design and intelligent CCTV are the products of efforts to suppress crime occurrence and to ensure the safety of citizen. Compared with existing public safety activities, these measures have a great significance in that they are intended to prevent crime in advance. The direct damage caused by a crime is so severe that it is difficult to recover and it causes serious indirect damage, too. There is growing recognition that it is best to avoid crime from the beginning. However, it should be possible to verify how preventable it is to check in these crime prevention projects and research. And, the underlying principles should be specifically verified as to what procedures and effects the detailed project activities have. Implementing projects according to urban environment design requires a huge budget. Intelligent CCTV also requires high cost.

In a project to redesign the urban environment to obtain the crime prevention effect, it should specifically clarified what types of facilities reduce certain types of crime. In this manner, when applied to other cities and other spaces, it is possible to devise a suitable solution for a specific case. Unless proper 'working' principles are identified and applied, the ambiguity of facilities and projects increases. Therefore, because of this, regional characteristics are not taken into account, which may end up with monotonous facilities and projects everywhere in the country. Currently, crime prevention projects in the Republic of Korea are showing such a monotonous pattern.

Introducing IoT to crime prevention projects may enhance the effectiveness of the project and adapt to various crime types. Adaptive countermeasures to various crime types can be devised. In addition, it has an advantage to clarify how the project details and facilities influence in crime prevention.

This study raises the necessity of comprehensive inclusion of various factors in the crime prevention project. In this study, it is discussed that existing projects and researches such as urban environment design project and intelligent CCTV project contain only a single aspect, which may be insufficient in the effectiveness of crime prevention. As an alternative, we suggest that crime risks should be assessed based on the inclusion of human factors such as spatio-temporal urban/environmental factors, the status of urban residents, and possible delinquency by potential criminals. We also proved that it is appropriate to establish a comprehensive risk assessment method by calculating the degree of involvement of environmental factors and human factors in crime occurrence as a risk

\section{Relevant Research}

\subsection{Environmental Criminology}

Environmental criminology deals with criminology by integrating criminology and urban architecture, as architects and urban planners such as J. Jacobs and O. Newman have promoted crime prevention through environmental design: CPTED). It aims to reduce crime opportunities by analyzing the causes of crime from buildings and areas [1].

The environmental design for crime prevention is as follows. First, the correlation between victims, criminals, and places is analyzed and a building or facility is planned so as to maximize the visibility to the public. Second, it is necessary to lead 
the public to specific/safe places through roads, walkways, landscaping and gates, and to block the entrance and exit of unauthorized individuals, making it difficult to assess crime targets. Third, it is necessary to design to have a territoriality, in which local residents can claim a license for an area. Fourth, by encouraging public's active use of designated places, it will naturally intensify surveillance and reduce the risk of crime in the neighborhood. Fifth, maintenance and management is imperative to ensure that any facility or public place can be used as it was originally designed. It is often referred that broken windows and graffiti act as 'No one care' signals for potential criminals to recognize disorder and illegal actions are easily tolerated.

\subsection{Routine Activity Theory}

The existing crime theories defined crime based on the 'crime motive' of criminals and conducted related research thereon. Unlike these theories, the routine activity theory focuses on 'opportunistic factors' centering on 'area'. The routine activity theory sought to prevent crime by changing the differential crime rate of the community from the change of the daily activities of the individual rather than the structural characteristics of the community. Potential criminals are assumed to be at the same level regardless of epoch. First, a crime occurs when a potential criminal discovers a suitable victim or object that is not being monitored by a capable guardian. It is analyzed that the probability that the three factors (potential criminals, absence of a capable guardian and suitable victims) occur simultaneously in time and space is greatly influenced by our daily activities including work areas, school, leisure activities and consumption [2].

\subsection{Rational Choice Theory}

In rational choice theory, crime is defined as an act that occurs according to the rational judgement of a criminals. Criminals are assumed to decide whether or not to commit crime by combining both the individual and the surrounding circumstances [3].

R. Clarke and D. Cornish proposed "Five principles with 25 techniques to reduce crime opportunities". The techniques to increase the effort are to 1) harden targets, 2) control access to facilities (or areas) 3) screen exits, 4) deflect offenders and 5) control tools and weapons. In order to facilities extended guardianship, other techniques to increase the risks are to 1) assist natural surveillance, 2) reduce anonymity, 3) utilize place managers and 4) strengthen formal surveillance. Other techniques to reduce the rewards are to 1) conceal targets, 2) remove targets, 3) identify property, 4) disrupt markets and 5) deny benefits. Other techniques to reduce provocations are to 1) reduce frustrations and stress, 2) avoid dispute, 3) reduce emotional arousal, 4) neutralize peer pressure and 5) discourage imitation. The rest techniques to remove excuses are to 1) set rules, 2) post instructions, 3) alert conscience, 4) assist compliance and 5) control drugs and alcohol.

\subsection{Crime Pattern Theory}

Crime pattern theory is a logic of explaining that crimes are committed with a certain spatial pattern and they are similar to criminal's routine activities. By predicting a crime site according to the analysis of criminal's activities, it proposes that it can help solve and prevent serial crimes including serial murders or serial rapes [4]. A crime site is a place to provide environmental cues that meet the criterion of the offender who learned about the characteristics of appropriate crime scenes. It is a theory that identifies the pattern of crime that distinguishes between crime inducing and restraining factors and crime object selection factors according to area type, building location, economic level, and surveillance potential. 


\subsection{Situational Crime Prevention Theory}

This theory is to design and manage the environment as systematically and continuously as possible for specific types of crime. It increases the perceived risks of arrest and crime conduct for potential criminals, however it decreases their rewards or crime justifications. Devices and means to prevent crime are in fact not effective in preventing crime. The theory analyzes that reducing crime opportunities does not actually reduce crime, but merely displaces it, thereby forming a fortified society. This theory suggested that a state-controlled society is a possibility by bringing the intervention of state power into society. Owing to the crime displacement effect, the reduction of crime opportunities does not reduce actual crime, but displace it to somewhere. The total number of crime remains the same. It also concludes that crime prevention activities in one area do not positively affect crime prevention in other areas [5].

\section{Crime by the Interaction of Environmental Factors and Human Factors}

\subsection{Environmental Factors and Crime}

In environmental criminology, there are places in an urban place where crime is likely to occur. It also found spatial characteristics that facilitates criminals to commit crimes. According to this study, a place where a criminal can easily observe potential victims, a place where a potential victim is easy to assess, a crime target, a place where a criminal can observe the vulnerability of a victim and a place with minimal interference or surveillance during committing a crime, are heavily interconnected with crime. If one looks for a space with these conditions, a place with low illumination, a place with little floating population and a vulnerable time for crime are the best candidates.

Although the illumination, floating population and vulnerable time are related to crime, it is still unreasonable to directly link them with the occurrence of crime. If no floating population exists in such a time and space, not a single crime can happen. It is reasonable to presume that if there is any small floating population - even if they exist discontinuously - a danger of crime may exist. Environmental factors are not absolute in estimating the risk of crime. The environmental factors that exclude the human factors themselves cannot be sufficient conditions for the proposition that crime risk increases. In other words, environmental factors, including human factors, can be a sufficient condition for the risk of crime.

\subsection{Human Factors and Crime}

No matter how dangerous the urban environment is, there will be no problem if the place is expected to have no floating population. A crime is a human act - a human being causes human and material damages. Factors affecting the occurrence of property crime are environmental factors and human factors. Sometimes, human factors can cause crime without environmental factors. For example, theft robbery occurs even if the crime prevention facilities are thorough and there are no environmental factors to facilitate crime. Meanwhile, there are two human factors in violent crime such as robbery, murder and rape - a criminal and a victim. A victim is a resident who lives in the space, an individual who executes crime is a criminal and an individual who is planning to execute crime is a potential criminal. In considering the trend of crime outbreak, the status of both victims and offenders should be carefully examined. In predicting the outbreak of crime, whether a crime victim can become a crime target and whether a potential criminal intends to commit a crime are key issues. These human factors may carry out a crime irrespective of environmental factors, but in many cases, a crime is executed in a crime prone area. 
Residents who lives in a crime prone area, are exposed defenselessly to crime-related behaviors. In the case of potential criminals, they appear in the crime site, take preliminary action on the crime, search for a crime object, observe the attraction level of a crime object, and wait for concealment after deciding to commit the crime. Although the state of the residents, potential criminals and crime preliminary behaviors, which could be victims of crime, may increase crime risk by themselves, the risk of crime increases when combined with environmental factors.

Therefore, this study analyzes that the risk of crime increases remarkably when environmental factors and human factors are combined.

\subsection{Complex Action of Environment Factors and Human Factors}

The risk of crime increases significantly, when complex factors such as environmental factors and human factors work together or interact each other. In other words, research that attempts to achieve crime prevention through environmental design is based on the assumption that potential criminals may move in and out, while residents live in the specific area. That is, crime prevention through environmental design is also reliant on a human factor.

Therefore, since the risk of crime increase significantly, when complex factors including environmental factors and human factors are reflected, crime prevention projects need to be implemented based on analysis of those two factors. Analysis of environmental factors and human factors in the improvement of environment for crime prevention should be included. For the analysis of human factors, the emergence and activity of residents and potential offenders should be considered. In chapter 4 , we prove and confirm these assertions in this study through case study analysis.

\section{Verification and Evaluation}

\subsection{Case Examples}

\section{1) Missing Case- Hyehee Song}

On February 13, 1999, Hyehee Song, who was a senior in high school in Hari Village, Doil-dong, Pyeongtaek, Gyeonggi Province, disappeared. Hyehee was missing just after she met a friend and took off a local bus at a local bus stop. This case highlights the possibility that the victim was kidnapped.

On the day, Hyehee went to Seojeong-ri, Songtan dong, in order to meet her boyfriend around 5:30 pm after school. At ten o'clock in the evening, when the last bus time was close, Heyhee took the last bus to go home. The bus driver at that time remembered that Hyehee took off the bus at the bus station in front of Do-il gas station the entrance of Hari in Doil-dong around 10:15 pm. He noted that a male with liquor smell took off at the same station with Hyehee. The bus stop where Hyehee took off was about $1 \mathrm{~km}$ away from her home and it was at night. The road to her house was a potential crime zone because of dark alleys surrounded by fields and hills. Hyehee walked in front, and the male walked a little behind her. This was the last appearance of Hyehee and she did not come back home after that.

\section{2) Murder Case - Middle School Girl in Pocheon}

It is anunsolved murder case of Hyun-ah Um, who was a junior of Dongnam middle school located at Songwoo-ri, Soheul-eup, Pocheon city in November 5, 2003. When the victim's body was found, her nail and toenail were found to be painted with red manicure. It is also called the 'manicure murder case'.

Around 4 p.m. on the day of the incident, Hyun-ah spent time with her four friends for fun after school and departed her friend's house around 6 p.m. Because she was late for 
her curfew, she was using a shortcut to home. After getting into the shortcut, she texted her mother that she would arrive soon and got disconnected. That evening, her mother reported her disappearance to the local police after her daughter had not been in the house at 9 p.m. and her cell phone was out of contact. It was about 800meter between the school and her house and she was able to reach within 10 minutes.

\section{3) Murder case - Female college student in Mokpo}

On October 15th, 2010, at 11:20 p.m., a senior nursing college student, Miss Cho, disappeared and was found to be dead in the following day. On the incident day, Miss Cho texted to her sister around 11:20 p.m., saying "I just finished my part-time job and now I am getting back to the hospital." The police found her jacket while checking the CCTV along her route. At 4:30 a.m. of the following day after the search, the police found Miss Cho dead in a drain between the hospital located at Sang-dong, Mokpo-si, Jeonlanam-do and the athletic park. This drain was just 20 meter away from the walkway, which was the casual Miss Cho's way back home.

4) Cheongju Women's disappearance case

On February 18, 2005, at the bus stop located on Route 36, Osong-eup, Cheongju-si, Chungcheongbuk-do, a housewife, Sangmuk Cho (age of 49) disappeared. On February 18, from 6 to 7 p.m., Mrs. Cho and members of the women's group had dinner together. After having a drink with dinner, they decided to go to a karaoke room around 8 o'clock. However, Mrs. Cho mentioned that she should go to Cheonan, and she didn't follow the group to the karaoke. Shortly before her disappearance, Mrs. Cho just purchased a house in Cheonan and she was going to that house. She rushed to the bust stop on Route 36 in order to get on a bus to Jochiwon station, but she had to wait for the next bus that would come 10 minutes later. A president of women's society in the neighboring town had last seen her around 8:10 p.m., waiting for a bus at the bus stop next to Route 36. Mrs. Cho, who suddenly disappeared while waiting for a bus to go to Cheonan, has not been spotted for last 12 years.

\section{5) Murder case - Female tutoring teacher in Donghae}

On March 14, 2006, a 24-year-old female tutoring teacher, Da-hye Kim was found dead in a well in Yakcheon village, Simgok, Mangsang-dong, Donghae-si, Gangwon-do. There were two similar incidents in Donghae-si. Three month after the murder case, on June 1, 2006, a middle-aged woman (in her 40s), who was trying to board her vehicle was suddenly attacked by an offender near an apartment in Bugok-dong, Donghae-si. The offender tried to sexually assault this woman but failed. Then, the perpetrator tried to kill her. When the victim fell unconscious, the perpetrator abandoned the victim to the roadside and fled. The place where this woman was abandoned was near the Yakcheon village well where the body of Da-hye Kim was found. The victim dramatically regained consciousness and reported this incident to the police. Three weeks later, on June 23, another similar incident occurred in another apartment in Bugok-dong. The victim was also a woman in her 40s. The killer hit the victim from the vehicle, pushed her into the vehicle and attempted to assault. However, when the victim screamed and stubbornly resisted, the perpetrator fled to a nearby alley. The murder of Da-hye Kim in March and the attempted abduction of two women in June were of considerable relevance.

These three events share many commonalities. The first was the place where the incident occurred. All three cases had occurred within a radius of 150meter of an apartment complex in Bugok-dong. The second is that all three events occurred in late evening hours around 9 p.m. The third point is that all women was assaulted by a perpetrator when she got in or out of the vehicle alone. All of the victims of the three cases have a common point of being a small, slender female around $150-\mathrm{cm}$ tall. It is also 
common that the victims were defeated only by pure brutal force without a weapon in action. Especially, in the murder case of Da-hye Kim and the first attempted abduction, offenders committed crimes in Bugok-dong and moved to Yakcheon Village, which is a common feature of the two cases.

\section{6) Murder case - Female college student in Hwaseong}

On October 27, 2004, a female, sophomore college student (Miss Roh) disappeared in Wow-ri, Bongdam-eup, Hwaseong-si, Gyeongi-do. She was found dead after 46 days. Around 8:35 p.m., Miss Roh passed Suwon University Station and got off with several passengers at the Wow-ri industrial complex in Bongdam-eup. The Wow-ri industrial complex was $3 \mathrm{~km}$ away from her home, and a stop which was close to her home than this stop was the Suwon University Station, which she had already passed. A scene that she took off at this station was caught on the bus CCTV. However, after that, her whereabouts became at large. At 11 p.m., a missing case was reported to the local police station in Taeahn. Police and her family had searched around her home till 3 a.m. of the following day, October 28. They were not able to find a single trace.

A real estate agent, Mr. Hong and a dentist, Mr. Kim, found a strange sight when there were looking around for a real estate transaction at Taebong Mountain in Botong-ri, Jungnam-myun, Hwaseong-si, Gyunggi-do on December 12. It was a human corpse whose bones were exposed with some remaining flesh, and was cannibalized by wild rats. This body was found to be Miss Roh's on December 14, as a result of the autopsy performed by the National Forensic Service.

7) Female college student missing case in Gumi

On August 8, 2002, around 2:08 p.m., Yoon-jung Jang, a female, college freshman, was missing in Gupo-dong, Gumi-si, Gyeongsangbuk-do. Around 2:08 p.m. on the day of her disappearance, Yoon-jung made a phone call to her boyfriend at a bus stop before going to her part-time job and promised to have lunch together. After leaving her last message that she would check the bus timetable, she disappeared.

Because it was early in the afternoon, it was unlikely for an offender to commit a crime at the bus stop. However, it is highly likely that the offender carefully observed Yoonjeong at the bus stop, took the same bus with her and committed a crime on her.

8) Murder case - Middle school girl in Gumi

On September 30, 2002, at 9:30 am, a female body was found at the Nakdong River, Gumi City. It was presumed that this body was slaughtered and thrown into the river after the abduction. The local police collected a piece of hair and fingerprints from the body and sent this information to the National Forensic Service. According to the test result, the subject was a middle school sophomore girl - last name Kim, who was missing in Okgyedong near Gupo-dong where Yoon-jeong was missing. There were extremely similarity between this case and the case of Yoon-jeong Jang described in 7), in terms of their missing places, which were bus stops, the distance between the bus stops, which was only 700 meter apart, the fact that both were going in the same direction, and the other fact that their phones were turned off in the opposite direction.

\section{9) Sexual harassment case in Dujeong-dong, Cheonan-si}

On June 15, 2013, at 11 p.m., a sexual harassment occurred in an open space between Dujeong station and Ian apartment in Dujeong-dong, Seobuk-gu, Cheonan-si. While the victim was moving from Dujeong station to Ian apartment, she was sexually harassed by the perpetrator in a vacant lot near the apartment construction site where the construction was not completed yet. 
10) Rape case in Ipjang-myun, Cheonan-si

On September 8, 2013, a rape incident occurred in a factory warehouse located in Girori, Ipjang-myun, Dongnam-gu, Cheonan-si. There is a convenience store (Ministop) at the entrance of the village near the main road in Giro-ri, Ipjang-eup. From here, an unsafe route exists among vulnerable districts encompassing abandoned factories and vineyard over a kilometer from the public health center to the village. The victim was taken to the neighboring factory warehouse by the stalking perpetrator and was raped.

11) Rape case - Anintoxicated female in Cheonan

On October 11, 2014, at 3:22 am, two Taekwondo instructors abducted a 23-year-old intoxicated female to their apartment and raped the victim.

Table 1. Crime Case Analysis

\begin{tabular}{|c|c|c|c|c|c|c|c|c|}
\hline No. & $\begin{array}{l}\text { Accident } \\
\text { history }\end{array}$ & Place & Time & Illumination & $\begin{array}{l}\text { Floating } \\
\text { population }\end{array}$ & concealment & Attention & Remarks \\
\hline 1 & $\begin{array}{l}\text { missing } \\
\text { (kidnap) }\end{array}$ & $\begin{array}{l}\text { Gupo-dong } \\
\text { Gumi-gu, } \\
\text { Gyeongbuk, } \\
\text { Bus stop }\end{array}$ & $\begin{array}{l}\text { PM } \\
2: 00\end{array}$ & Day & $\begin{array}{l}\text { Little } \\
\text { (Alone) }\end{array}$ & No & High & $\begin{array}{l}\text { Guess of } \\
\text { rape } \\
\text { killings }\end{array}$ \\
\hline 2 & Murder & $\begin{array}{l}\text { Okgyedong, } \\
\text { Gumi City, } \\
\text { Gyeongbuk, } \\
\text { Bus stop }\end{array}$ & Day & Day & $\begin{array}{l}\text { Little } \\
\text { (Alone) }\end{array}$ & No & High & Dead \\
\hline 3 & $\begin{array}{l}\text { missing } \\
\text { (kidnap) }\end{array}$ & $\begin{array}{l}\text { Osong Eup, } \\
\text { Cheongju, } \\
\text { Chungbuk, } \\
\text { Bus stop }\end{array}$ & $\begin{array}{l}\text { PM } \\
7: 00\end{array}$ & Low & $\begin{array}{l}\text { Little } \\
\text { (Alone) }\end{array}$ & No & High & $\begin{array}{l}\text { Guess of } \\
\text { rape } \\
\text { killings }\end{array}$ \\
\hline 4 & $\begin{array}{l}\text { missing } \\
\text { (kidnap) }\end{array}$ & $\begin{array}{l}\text { Doyle-dong, } \\
\text { Pyeongtaek, } \\
\text { Gyeonggi- } \\
\text { do, } \\
\text { Doylegas } \\
\text { station }\end{array}$ & $\begin{array}{l}\text { PM } \\
10: 00\end{array}$ & $\begin{array}{l}\text { High } \\
\text { (gas station) }\end{array}$ & $\begin{array}{l}\text { Little } \\
\text { (Alone) }\end{array}$ & Yes & High & $\begin{array}{l}\text { Guess of } \\
\text { rape } \\
\text { killings }\end{array}$ \\
\hline 5 & rape & $\begin{array}{l}\text { Ibjang- } \\
\text { myen, } \\
\text { Sebuk-gu, } \\
\text { Cheonan, } \\
\text { Chungnam }\end{array}$ & $\begin{array}{l}\text { PM } \\
10: 30\end{array}$ & $\begin{array}{l}\text { High } \\
\text { (convenience } \\
\text { store }\end{array}$ & $\begin{array}{l}\text { Little } \\
\text { (Alone) }\end{array}$ & Yes & High & $\begin{array}{l}\text { Move / } \\
\text { Track }\end{array}$ \\
\hline 6 & $\begin{array}{l}\text { Sexual } \\
\text { harassment }\end{array}$ & $\begin{array}{l}\text { Baebang- } \\
\text { Eup, Asan } \\
\text { City, } \\
\text { Chungnam }\end{array}$ & $\begin{array}{l}\text { PM } \\
10: 00\end{array}$ & $\begin{array}{l}\text { High } \\
\text { (convenience } \\
\text { store }\end{array}$ & $\begin{array}{l}\text { Little } \\
\text { (Alone) }\end{array}$ & Yes & High & $\begin{array}{l}\text { Move / } \\
\text { Track }\end{array}$ \\
\hline 7 & rape & $\begin{array}{l}\text { Jiksan-Eup, } \\
\text { Sebuk-gu, } \\
\text { Cheonan, } \\
\text { Chungnam }\end{array}$ & & $\begin{array}{l}\text { High } \\
\text { (convenience } \\
\text { store }\end{array}$ & $\begin{array}{l}\text { Little } \\
\text { (Alone) }\end{array}$ & Yes & High & $\begin{array}{l}\text { Move / } \\
\text { Track }\end{array}$ \\
\hline 8 & rape & $\begin{array}{l}\text { Dujeng- } \\
\text { dong, } \\
\text { Sebuk-gu, } \\
\text { Cheonan, } \\
\text { Chungnam }\end{array}$ & & $\begin{array}{l}\text { High } \\
\text { (Around the } \\
\text { station }\end{array}$ & Floating & No & unidentified & $\begin{array}{l}\text { Move / } \\
\text { Track }\end{array}$ \\
\hline
\end{tabular}

\subsection{Case Analysis}

Causes of these events are analyzed as follows. The following analysis summary shows 
whether there is a correlation between the factors that are related to the occurrence of an event and the event itself.

Case 1) occurred during the time of frequent crime. Observations were made in a brightly illuminated area by getting off at the gas station, and the incident occurred in a dark alley. Thus, spatial factor without illumination and floating population affected this crime. A high school girl moved alone to expose her charm as a victim and her vulnerability of no protection and no guardians. The offender seemed to have made preliminary activities such as observing and searching for a victim.

Case 2) occurred around 6 p.m. to 6:30 p.m., which was not a typical time for crime. A spatial factor affected this case, in that the incident place was only known for local residents, which had less floating population. Moving alone by a middle-school girl became a target for a criminal. The criminal seemed to have engaged in preliminary activities, such as concealing in a place off the beaten path, or stalking and approaching her from the main road.

Case 3) was an event in which spatio-temporal, individual conditions and criminal preparatory activities all affect, as in case 1).

Case 4) did not occur in a vulnerable time as in Case 2). It seems that an individual status of a victim were exposed as a criminal goal. The offender quickly moved with a vehicle and searched for his victim.

Case 5) seems to be an event, in which various factors such as 1) case affect, except that the place occurred in a residential area.

Cases 6), 7) and 8) occurred neither in vulnerable time nor at a place with low illumination. They appeared to occur when there was little floating population nearby. Offenders verified victims' level of defense and attractiveness by observation.

Cases 9), 10) and 11) showed that both spatio-temporal factors and individual status were involved in the cases as in Case 1). Case 11) showed that the criminal did not plan to commit the crime in advance. The criminal impulsively committed the crime after observing victim's significant vulnerability during the motion.

\subsection{Evaluation}

All of the cases analyzed above can be regarded as the interaction between the environmental factors and the human factors, or as a result of the comprehensive action of the both. Therefore, in order to improve an environment for crime prevention, it is necessary to consider lifestyle and behavior of local residents using the specific area. For example, in case of bus stops, it is imperative not only to reinforce illumination, but also to strengthen security instruments. It is also necessary not only to focus on solving problems in crime-ridden areas, but also to improve surrounding environment connected to the crime-ridden areas. Simultaneously, the living and behavioral patterns of residents should be closely analyzed and reflected in the environment improvement project. If so, each region has its own characteristics, and there are differences in behavioral patterns and lifestyles according to the level of living and living environments of local residents.

As an expected result, there will not be the exactly same crime prevention subjects anywhere in the country. It is expected that crime prevention facilities and project contents will be customized in each region.

Similarly, surveillance and law-enforcing activities on human factors can be carried out in consideration of environmental factors. It is possible to plan and implement policing activities, such as patrolling areas where crime is frequent, areas similar to crime-prone areas and other places where potential criminals may prefer when facility security for crime-prone area is strengthened. 


\section{Conclusion}

The recent development of IoT allows consumer's real world cognition and intelligent services without human intervention. IoT has been applied to numerous fields such as medicine, tourism, logistics and education and has improved each field. In this study, we suggested that both the environmental improvement and the human factors should be analyzed and considered in order to prevent crime by using IoT. Environmental improvement alone has a limit that the risk of crime is not properly predicted, thereby limiting a chance to avoid the risk. In addition, surveilling human factors alone also has a limitation that it cannot predict the risk of crime properly. We raised issues on this matter, and proposed and analyzed that environmental factors and human factors are closely related and affect the crime itself. In order to demonstrate the validity of this proposal, we analyzed the existing incidents and verify its validity. Therefore, crime prevention research and projects using IoT need to include not only the contextual reasoning based on the environmental factors related to crime, but also the proper analysis of the lifestyle of residents and the emergence and activities of potential criminals.

\section{Acknowledgments}

This research was supported by Basic Science Research Program through the National Research Foundation of Korea (NRF) funded by the Ministry of Education (NRF2015R1D1A3A01017968).

This paper is a revised and extended version of a paper entitled [An Integrated Contextual Recognition Method based on the Internet of Things for Intelligent Crime Prevention] presented at [FGIT2017, Daejeon University, Korea, December21-23, 2017].

\section{References}

[1] P. M. Cozens, "Sustainable Urban Development and Crime Prevention Through Environmental Design for the British City", Towards an Effective Urban Environmentalism for the 21st Century. Cities, vol. 19, no. 2, (2002), pp. 129-137.

[2] C. P. Travis, K. Holtfreter and D. R. Michael, "Routine Online Activity and Internet Fraud Targeting", Extending the Generality of Routine Activity Theory, vol. 47, no. 3, (2010), pp. 267--296.

[3] B. C. Derek and V. C. Ronald, "The Reasoning Criminal", Rational Choice Perspectives on Offending. Transaction Publishers, (2014).

[4] R. Wortley and L. Mazerolle, "Environmental Criminology and Crime Analysis", Routledge, (2013).

[5] R. V. G. Clarke, "Situational Crime Prevention: Theory and Practice", Journal of Criminology, vol. 20, no. 2, (1980), pp. 136-147.

[6] D. P. Douglas, W. M. John and B. T. Ralph, "The Physical Environment of street block and resident perceptions of crime and disorder: Implications for theory and measurement”, Journal of Environmental Psychology, vol. 12, (1992), pp. 21-34.

[7] R. V. G. Clarke and M. Felson, "Routine Activity and Rational Choice", Transaction Publishers, (1993).

[8] E. Ostrom, "A Behavioral Approach to the Rational Choice Theory of Collective Action", Presidential Address, American Political Science Association, 1997, vol. 92, no. 1, (1998), pp. 1-22.

[9] S. L. Gabbidon and H. T. Greene, "Race, Crime, and Justice", A Reader. Routledge, (2013).

[10] R. V. G. Clarke, K. Bullock and N. Tilley, "Situational Prevention of Organised Crimes", Taylor \& Francis, (2010).

\section{Authors}

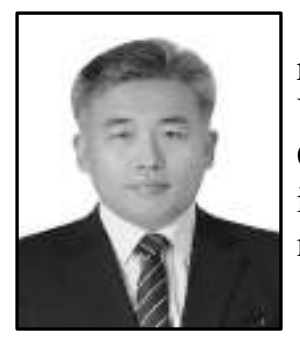

Donghyeok Suh, he is a professor at Dankook University. He received the M.S. degrees in computer engineering from Hoseo University in 2005 and the Ph.D. in computer science from Chungbuk National University in 2012. His research interests included in stream data processing and data fusion in wireless sensor network. 


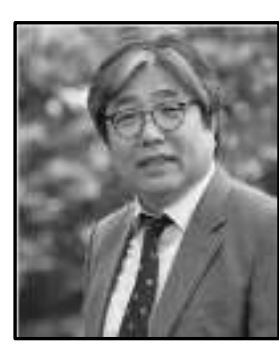

Kyung-soo Cho, he is a professor at Namseoul University. $\mathrm{He}$ received the B.S. degree in Architecture from Hongik University in 1986, and the M.S.in 1988 and Ph.D. in Architecture from Hongik University in 2000. His research interests are included in information technology architecture and data fusion in wireless sensor network.

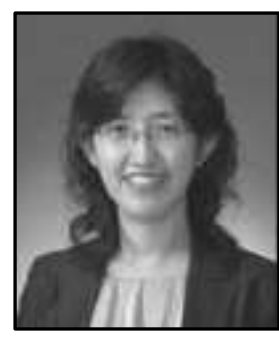

Jeong-hwa Song, she is a professor at Namseoul University. She received the B.S. degree in Housing and interior design from Yonsei University in 1990, and the M.S. and Ph.D. in Housing and interior design from Yonsei University in 2005. Her research interests are included in data fusion in wireless sensor network and Ubiquitous Housing. 
International Journal of Grid and Distributed Computing

Vol. 11, No. 2 (2018) 